Mohammed A. Abdulla BDS, MSc (Asst Lec.)

\title{
Impact Strength of Maxillary Complete Dentures Fabricated From Different Heat Cured Acrylic Resin Denture Base Materials
}

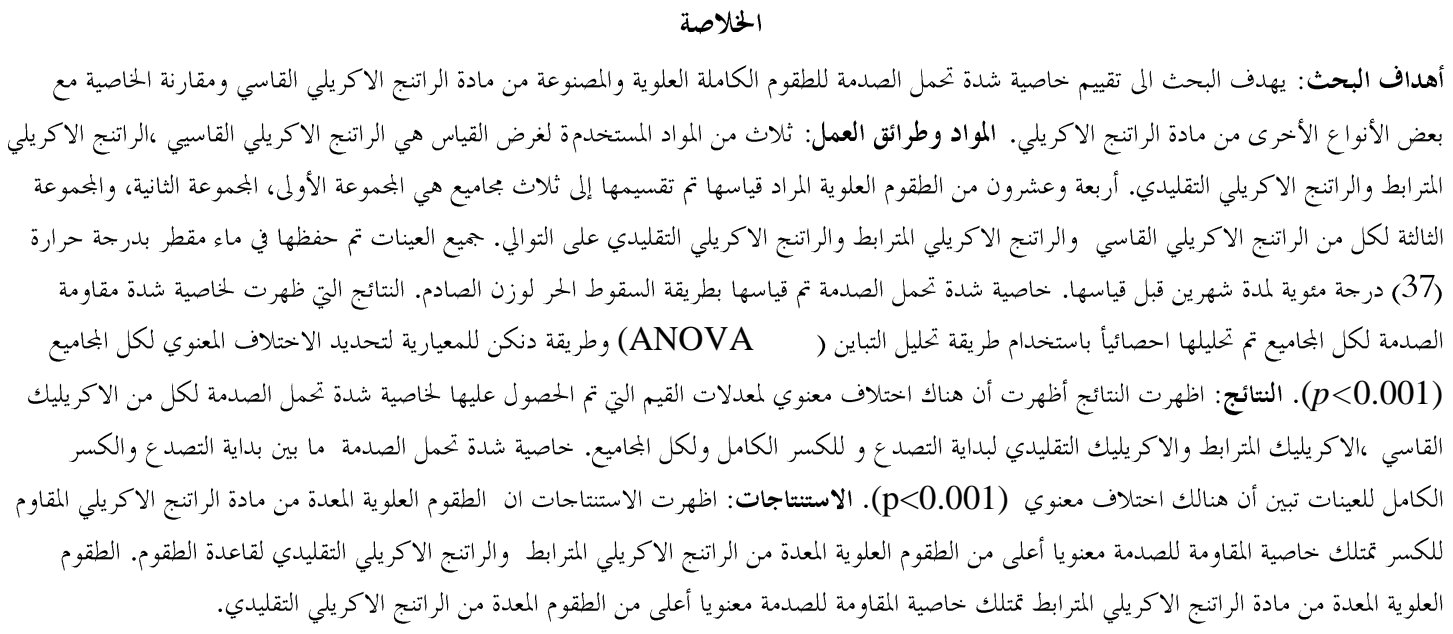

ABSTRACT

AIMS: Evaluation of the impact strength of maxillary complete dentures fabricated from new type high impact heat-cured acrylic denture base material and comparison with other types of acrylic resin denture base materials. MATERIALS AND METHODS: Three types of materials were used in this study, high impact heat-cured acrylic resin; cross-linked acrylic resin (no cadmium); and conventional heat-cured acrylic resin. Twenty four maxillary complete dentures were fabricated to be tested and divided into three groups. Group 1, Group 2, and Group3 for high impact acrylic resin, cross-linked acrylic resin, and conventional heat- cured resin, respectively. Before testing, all specimens were stored in distilled water at $37^{\circ} \mathrm{C}$ for 2 months. The impact strengths $(\mathrm{J})$ of the dentures were measured with a falling-weight impact test. The impact strengths of both groups were compared by a repeated measures analysis of variance (ANOVA) and Duncan's Multiple Analysis Range Test to determine the significant difference among the tested groups at $(p<0.001)$ level of significance. RESULTS: There is a significant difference of the mean values of impact strengths for high impact acrylic resin, cross linked acrylic resin and conventional acrylic resin denture base materials at crack initiation and complete fracture. The impact strength between crack initiation and complete fracture within each group was significantly different $(p<0.001)$ for all the groups, and more energy was needed for complete fracture than that for crack initiation for the high impact strength acrylic resin. CONCLUSIONS: Maxillary complete dentures made from high impact acrylic resin denture base material have significantly higher impact strength than that of maxillary complete denture made from cross-linked and conventional acrylic resin denture base materials. Maxillary complete dentures made from cross-linked acrylic resin denture base material have significantly higher impact strength than that made from conventional acrylic resin denture base materials.

Keyword: high impact, cross-linked, impact strength, impactor

Abdulla MA. Impact Strength of Maxillary Complete Dentures Fabricated From Different Heat Cured Acrylic Resin Denture Base Materials. Al-Rafidain Dent J. 2012; 12(1): 24-31.

Received: 19/4/2010 Sent to Referees: $22 / 4 / 2010$

Accepted for Publication: 15/6/2010

\section{INTRODUCTION:}

One of the most widely used material in prosthetic dentistry is polymethymethacry- late. Since, it was introduced to dentistry, it has been successfully used for denture base, artificial teeth, and impression trays. 
The primary cause of denture break within a few years after fabrication is the impact failure when the denture is accidentally dropped on a hard surface or by fatigue when the denture base deforms repeatedly through occlusal forces ${ }^{(1,2)}$. The fracture of dentures may be related to the mechanical properties of the acrylic resin or may be due to multiplicity of factors leading to failure of the denture base material ${ }^{(3)}$. Impact strength data and fracture characteristics depend upon many factors including material selection, geometry of the specimen, fabrication variables, stress concentrations, position of the specimen, and temperature. Stress concentrations are the main contributors to impact failure in dentures and include notches, scratches, cuts, depressions, sharp corners, holes, grooves, rough surfaces, textured surfaces, sudden changes in thickness, foreign particles, or gas inclusions, the surrounding temperature also effect on the impact strength of a material $^{(4,5)}$. One of the method is used to increase the impact strength by the incorporation of a rubber phase in the bead polymer like butadiene-styrene rubber. This modification increases the impact strength, which is accompanied by some increase in transverse deflection ${ }^{(6)}$. Many researchers have been used glass fibers, metal wires, and metal plates to improve the mechanical properties of acrylic resin, especially fatigue resistance, impact strength, and flexural strength ${ }^{(7-13)}$.

For maxillary dentures most fractures are caused by a combination of fatigue and impact, whereas for mandibular dentures $80 \%$ of fractures are cause by impact ${ }^{(14)}$. In most situations, fractures occur in the midline of denture base more often in maxillary dentures than in mandibular dentures. To improve mechanical properties, the chemical composition of a resin can be modified or reinforced with highresistance fibers, thus obtaining a so-called "high-impact" resin ${ }^{(15)}$.

The aim of this study was to measure the impact strengths of maxillary complete dentures fabricated from new type high impact heat-cured acrylic denture base materials and to compare the results with other types of acrylic resin denture base materials (cross-linked, and conventional heat-cured).

\section{MATERIALS AND METHODS}

Twenty four maxillary dentures were fabricated to be tested (eight dentures for each materials). Three types of acrylic resin denture base materials were used in this study (Table 1), and divided into three groups. Group 1, Group 2,and Group3 for High impact acrylic resin, Cross-linked acrylic resin, and Conventional heat-cured resin, respectively. Identical maxillary casts of edentulous patient were duplicated with a silicon mold. A Record base was fabricated from visible light- cured (VLC) acrylic resin material (Megadent, Germany). A wax occlusal rim (T.P. Regular modeling wax, Major Prodotti Dentari S.P.A, Italy) was adapted on the record base and then the cast with the record base and occlusal rim was mounted on a semi-adjustable articulator. Acrylic resin teeth (Anterior M, A2; Posterior M, A2, Seif, Syrian) were arranged according to the oriented occlusion rim. The surface of the labial and buccal flanges were contoured to reproduce the appearance of natural gingival, then the dentures were flasked.

Table (1): Types of acrylic resin denture base materials

\begin{tabular}{|c|c|c|}
\hline Products & Manufacturer & Specification No. \\
\hline $\begin{array}{l}\text { Implacryl, High impact heat curing } \\
\text { acrylic resin }\end{array}$ & $\begin{array}{l}\text { High Impact Acryl, Vertex den- } \\
\text { tal, Netherlands }\end{array}$ & $\begin{array}{l}\text { ISO } 1567 \\
\text { Type } 1\end{array}$ \\
\hline $\begin{array}{l}\text { Reguler, conventional heat curing } \\
\text { acrylic resin }\end{array}$ & $\begin{array}{l}\text { Regular, Vertex dental, Nether- } \\
\text { lands }\end{array}$ & $\begin{array}{c}\text { Class } 1 \\
\text { ISO } 1567 \\
\text { Type } 1 \\
\text { Class } 1\end{array}$ \\
\hline $\begin{array}{c}\text { RESPAL }^{\mathrm{NF}} \text {, Cross-linked (no cadmium) } \\
\text { heat curing acrylic resin }\end{array}$ & $\begin{array}{l}\text { Cross-linked, Salmoiraghi Den- } \\
\text { taria S.r.L, Italy }\end{array}$ & $\begin{array}{l}\text { ISO } 1567 \\
\text { Class } 1\end{array}$ \\
\hline
\end{tabular}


The acrylic resin powder and liquid were mixed according to manufacturer's instruction (powder-liquid ratio 10/21 ml/g by weight ) for high Impact Acryl , (powder-liquid ratio 10/22 $\mathrm{ml} / \mathrm{g}$ by weight ) for regular conventional heat curing acryl, and (powder-liquid ratio 10/21 $\mathrm{ml} / \mathrm{g}$ by weight) for cross-linked heat curing resin. Conventional packing and curing were used. The thickness of the dentures $(2.5 \mathrm{~mm})$ was measured by a digital vernier caliper (LEZACO, ART.2771, China).

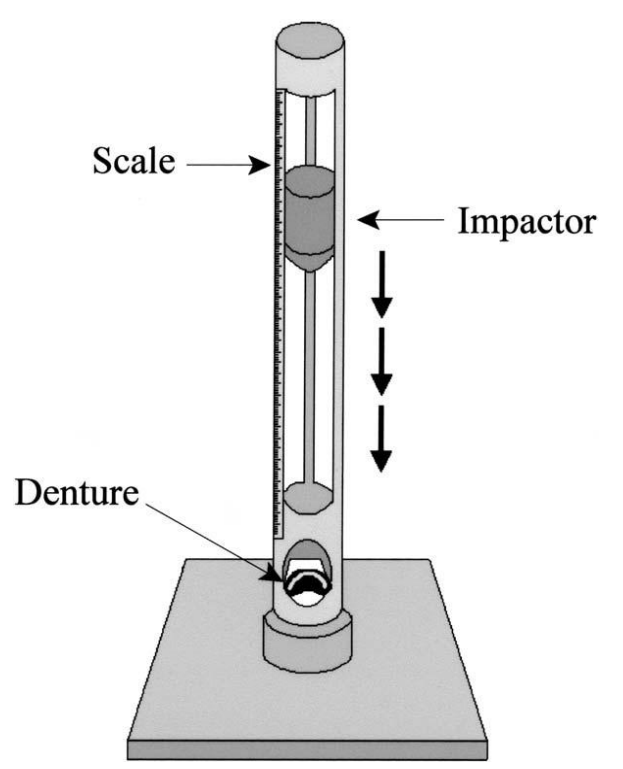

Figure (1): Schematic diagram of Falling-impact test.
Differences in the dimensions were carefully eliminated by trimming the dentures to predetermined dimensions. All dentures were stored in distilled water at $37^{\circ} \mathrm{C}$ for two months before testing ${ }^{(16)}$. Testing was carried out at $23^{\circ} \mathrm{C} \pm 0.5^{\circ} \mathrm{C}$. The testing procedure used in this study was done according to Kim and Watts ${ }^{(16)}$. The impact test was performed with a specially apparatus designed for this testing consisting of a plastic tube and impactor (Figures $1,2)$.

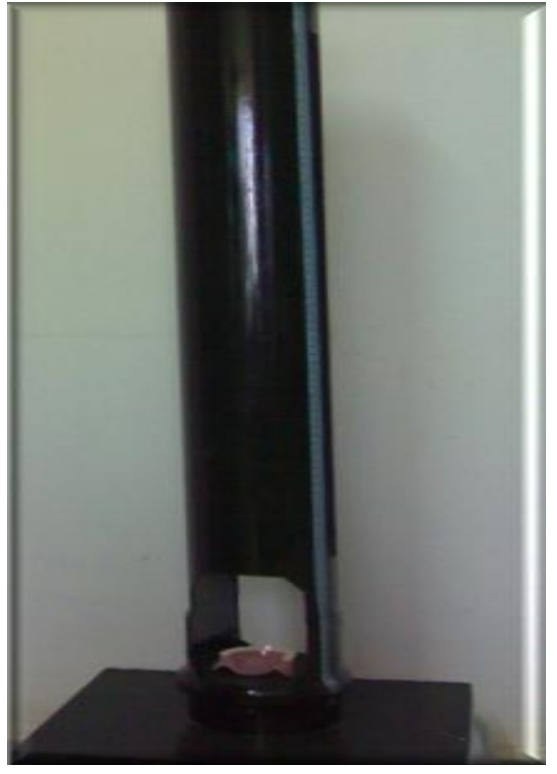

Figure (2): Falling-weight impact test.
The tube, which guided the direction of impactor, had two windows to minimize the resistance between the tube and the impactor. The impactor was made with hard wood and had a hemi-sphere end of

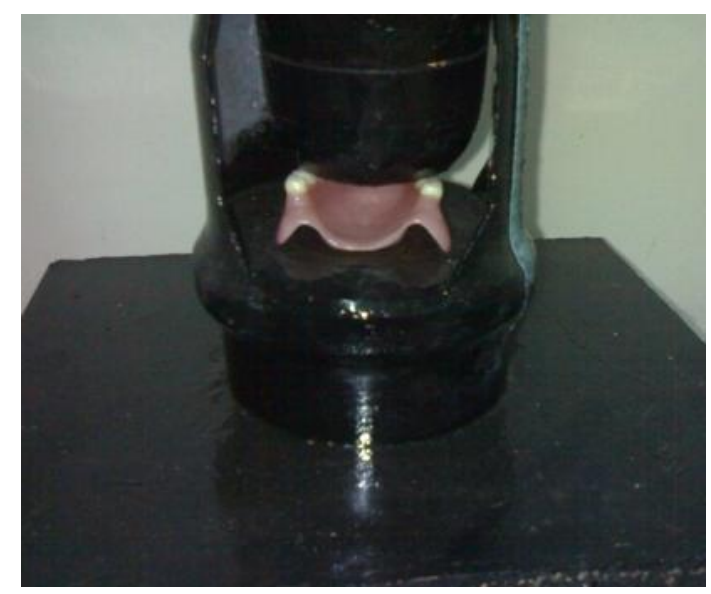

radius $50 \mathrm{~mm}$ and a mass of $0.876 \mathrm{~kg}$. the testing apparatus was placed on a flat surface. The denture was placed on the small table in the tube (Figure 3).

Figure (3): Denture position 
The impactor was dropped onto the denture through the tube. When the impactor was released, the starting height was recorded. If the denture was not broken with an initial starting height of $60 \mathrm{~cm}$. the test was repeated from the same height until the denture broke. If the denture was still un broken after 40 such repetitions, the height was increased to $80 \mathrm{~cm}$. The energy absorbed in cracking and breaking each denture was calculated using the following formula ${ }^{(17)}$ :

$$
\mathbf{i = n} \quad \mathrm{E}=\operatorname{mg} \sum \mathrm{h}_{\mathrm{I}} \quad \mathrm{i}=\mathbf{1}
$$

Where

$\mathrm{E}=$ impact strength (impact energy)

$\mathrm{m}=$ weight of impactor $(0.876 \mathrm{~kg}$.)

$\mathrm{g}=$ acceleration of gravity $\left(9.8 \mathrm{~m} / \mathrm{sec}^{2}\right)$

$\mathrm{h}=$ the height in meter from which the impactor was dropped

$\mathrm{n}=$ number of impacts

This formula was used to calculate the impact strength energy (J) through calculate the summation of multiplying the weight of impactor $(0.876 \mathrm{~kg}$.) with acceleration of gravity $\left(9.8 \mathrm{~m} / \mathrm{sec}^{2}\right)$ depending on the number of impacts in which the impactor was dropped. Two values of energy were determined for each group. Once was at the crack initiation (energy needed to initiate a crack in denture), and the other was at the complete fracture (energy needed to break the denture completely). After data collection, mean values and standard deviations were calculated and compared by a repeated measures analysis of variance (ANOVA). Duncan's Multiple Range Test was used to determine the significant differences among the tested groups at $(\mathrm{p}<0.001)$ level. T-test was used for each group to determine the significant differences between crack initiation and complete fracture energy.

\section{RESULTS}

The mean values and standard deviations of impact strengths are shown statistically in (Tables 2,3).

Table (2): Mean, Standard Deviation, and Duncan's Multiple Rang Test of the impact strength for the three groups of acrylic resin materials (crack initiation).

\begin{tabular}{ccc}
\hline $\begin{array}{c}\text { Types of } \\
\text { acrylic resin }\end{array}$ & $\begin{array}{c}\text { Crack initiation } \\
\text { Mean } \pm \text { SD }\end{array}$ & Duncan's group \\
\hline High Impact heat cured & $235.67 \pm 8.220$ & $\mathrm{~A}$ \\
Cross-linked heat cured & $129.19 \pm 5.316$ & $\mathrm{~B}$ \\
Conventional heat cured & $51.38 \pm 3.560$ & $\mathrm{C}$ \\
\hline
\end{tabular}

$\mathrm{SD}=$ standard Deviation, $\mathrm{N}=$ Number of samples, Mean with different letters vertically statistically significant.

Table (3): Mean, Standard Deviation, and Duncan's Multiple Rang Test of the impact strength for the three groups of acrylic resin materials (complete fracture).

\begin{tabular}{lcc}
\hline Types of acrylic resin & $\begin{array}{c}\text { Complete fracture } \\
\text { Mean } \pm \text { SD }\end{array}$ & $\begin{array}{c}\text { Duncan's } \\
\text { group }\end{array}$ \\
\hline High Impact heat cured & $243.91 \pm 7.401$ & $\mathrm{~A}$ \\
Cross-linked heat cured & $139.29 \pm 3.140$ & $\mathrm{~B}$ \\
Conventional heat cured & $54.01 \pm 3.256$ & $\mathrm{C}$ \\
\hline
\end{tabular}

$\mathrm{SD}=$ standard Deviation, $\mathrm{N}=$ Number of samples, Mean with different letters vertically statistically significant.

The impact strength of the high impact acrylic resin, cross linked acrylic resin and conventional acrylic resin denture base materials were: $(235.67 \pm 8.220 \mathrm{~J})$, 
$(129.19 \pm 5.31 \mathrm{~J})$, and $(51.38 \pm 3.560 \mathrm{~J})$ at crack initiation, and $(243.91 \pm 7.401 \mathrm{~J})$, $(139.29 \pm 3.140 \mathrm{~J})$, and $(54.01 \pm 3.256 \mathrm{~J})$ at complete fracture, respectively. Analy- sis of variance (ANOVA) tests showed that there are significant differences $(\mathrm{p}<0.001)$ at crack initiation and complete fracture among the groups (Tables 4,5 ).

Table (4): Analysis of Variance (ANOVA) for levels of the three groups of acrylic resin materials at Crack initiation.

\begin{tabular}{|cccccc}
\hline Between the three groups & $\begin{array}{c}\text { Sum of } \\
\text { Squares }\end{array}$ & df & Mean Square & F & P- value \\
\cline { 2 - 7 } & 136952.4 & 2 & 68476.209 & 1893.031 & $0.001^{*}$ \\
\hline
\end{tabular}

*Significant differences, $\mathrm{df}=$ degree of freedom

Table (5): Analysis of Variance (ANOVA) for levels of the three groups of acrylic resin materials at Complete fracture

\begin{tabular}{lllllll}
\hline Between the three groups & $\begin{array}{c}\text { Sum of } \\
\text { Squares }\end{array}$ & df & Mean Square & F & P-value \\
\cline { 2 - 7 } & 144737.6 & 2 & 72368.791 & 2884.886 & $0.001^{*}$ \\
\hline
\end{tabular}

*Significant differences, $\mathrm{df}=$ degree of freedom

Duncan's Multiple Analysis Range Tests (at crack initiation and complete fracture energies) showed that high impact acrylic resin showed significantly higher impact strength followed by cross-linked heat-cured, while conventional heat-cured showed significantly lowest impact strength (Tables 2,3). Tables $(6,7,8)$ showed that the impact strength between crack initiation and complete fracture was significantly difference $(\mathrm{p}<0.001)$ for each of the three groups, and more energy was needed for complete fracture than that for crack initiation.

Table (6): t-test for quality of mean for the crack initiation energy and complete fracture of the high impact acrylic resin denture base material

\begin{tabular}{lcccc} 
High impact acrylic resin & $\mathbf{t}$ & Df & SE & P-value \\
\cline { 2 - 5 } & -7.941 & 7 & 1.0373 & $0.001^{*}$ \\
\hline
\end{tabular}

* Significant differences, $\mathrm{df}=$ degree of freedom, $\mathrm{SE}=$ Standard error

Table (7): t-test for quality of mean for the crack initiation energy and complete fracture of the cross-linked acrylic resin denture base material

\begin{tabular}{ccccc}
\hline Cross-linked acrylic resin & T & Df & SE & P-value \\
\cline { 2 - 5 } & -11.049 & 7 & 0.91389 & $0.001^{*}$ \\
\hline
\end{tabular}

* Significant differences, $\mathrm{df}=$ degree of freedom, $\mathrm{SE}=$ Standard error 
Table (8): t-test for quality of mean for the crack initiation energy and complete fracture of the conventional acrylic resin denture base material

\begin{tabular}{ccccc}
\hline Conventional acrylic resin & T & Df & SE & P-value \\
\cline { 2 - 5 } & -4.956 & 7 & 0.53216 & $0.003^{*}$ \\
\hline
\end{tabular}

* Significant differences, $\mathrm{df}=$ degree of freedom, $\mathrm{SE}=$ Standard error

\section{DISCUSSION}

Impact strength is a measure of the energy absorbed by a material when it is broken by a sudden blow. In the fallingweight impact test, the amount of energy required to break the material is determined by the weight of the object and the height from which it was dropped. In this study, the falling weight impact test was designed to simulate clinical conditions with upper dentures of conventional size, as test conditions that closely simulate impact conditions in service are also important to predict failure. The dimensions of the specimens approximated the dimensions of actual prostheses fabricated by the conventional method. Therefore, the results from this test may be more clinically relevant ${ }^{(16)}$.

Statistically, it was shown that Tables (6-8) there is significant differences within all groups between crack initiation and complete fracture energy required; this was excepted clinically that many cases of maxillary dentures were subjected to fatigue remain cracked before repairing for a period of time till it fractured completely. Clinical studies have shown midline fracture to be a common problem in upper and lower dentures ${ }^{(18)}$ and this had been shown during testing the upper dentures during the crack initiation and finally complete fracture. The primary cause of this failure, with the exception of accidental damage, is flexural fatigue stress exerted by repeated masticatory forces. A factor that can accelerate the initiation and the propagation of surface cracks is the presence of labial and lingual frenum. The base has to be shaped to accommodate the frenum, and a deep notch can promote stress concentration ${ }^{(18)}$.

In this study, specimens were conditioned in distilled water for two months to show the effect of immersing the dentures on the impact strength properties. One of the properties of acrylates is water sorption and release, which causes dimensional instability, thus subjecting the material to internal stresses that may result in crack formation and, eventually, fracture of the denture. Water molecules diffused between the macromolecules of the material and thus forced them apart. This behavior affects dimensional behavior and denture stability; therefore, water sorption and solubility of these materials should be as low as possible ${ }^{(19,20)}$.

The mechanical properties of the materials in relation to their chemical composition was not analyzed in this study. Most of the heat polymerizable polymers provided in powder and liquid form, classified by ISO in Type 1 Class 1 , present similar compositions, the powder contains polymethylmethacrylate in approximately 95\%, benzoyl peroxide as initiator $(1 \%)$ and other additives in the remaining $4 \%$ (plasticizer, opacifier and coloring substances); the liquid contains methylmethacrylate and dimethacrylate as cross linking agents in variable ratios, often around 90:10, and other substances in a small percentage (hydroquinone as a reaction inhibitor and others). Various authors have demonstrated the importance of the crosslinking agent on the mechanical properties of the denture base materials in resistance to surface cracking and complete fracture which is much better than the conventional heat-cured acrylic resin material $^{(21)}$.

From results obtained, a fast polymerization cycle improved the impact strength of high impact, in which both the initial and final temperatures were $100^{\circ} \mathrm{C}$. Due to the well known concept that during the exothermic reaction of polymerization, the released heat has to be added to that generated externally, raising the resin temperature. ${ }^{(22)}$

The fast polymerization cycle for heatcured acrylic resin proved to increase the flexural strength, although the manufacturer recommends the use of this cycle 
only if the thickness of the prosthesis thickness is $\geq 3 \mathrm{~mm}$. ${ }^{(23)}$.

\section{CONCLUSIONS}

Maxillary complete dentures made from high impact acrylic resin denture base material have significantly higher impact strength than that of maxillary complete denture made from cross-linked and conventional acrylic resin denture base materials. Maxillary complete dentures made from cross-linked acrylic resin denture base material have significantly higher impact strength than that made from conventional acrylic resin denture base materials.

\section{REFERENCES}

1. Gutteridge D. The effect of including ultra-high modulus polyethylene fiber on the impact strength of acrylic resin. Br Dent J. 1988; 164:177-180.

2. Manley T, Bowman A, Cook M. Denture bases reinforced with carbon fibers. Br Dent J. 1979; 146:25.

3. Jagger D, Harrison A, Jandt K. Review -The reinforcement of dentures. J Oral Rehabil. 1999; 26:185-194.

4. Uzun G, Hersek N, Tincer T. Effect of five woven fiber reinforcements on the impact and transverse strength of a denture base resin. J Prosthet Dent. 1999 ; 81: 616-620.

5. Niesen L, Landel R. Mechanical properties of polymers and composite. 2nd ed. New York: Marcel Dekker; 1993. Pp. 307-317.

6. Stafford G, Bates J, Huggett R, Handley R. A review of the properties of some denture base polymers. J Dent. 1980;8: 292-306.

7. Vallittu P, Narva K. Impact strength of modified continuous glass fiberpoly(methyl methacrylate). Int J Prosthodont. 1997;10: 142-148.

8. Kanie T, Fujii K, Arikawa H, Inoue K. Flexural properties and impact strength of denture base polymer reinforced with woven glass fibers. Dent Mater. 2000 ;16: 150-158.

9. Nagai E, Otani K, Satoh Y, Suzuki S. Repair of denture base resin using woven metal and glass fiber: Effect of me- thylene chloride pretreatment. J Prosthet Dent. 2001;85:496-500.

10. Bertassoni L, Marshall G. Effect of pre- and post polymerization on flexural strength and elastic modulus of impregnated, fiber reinforced denture base acrylic resins. J Prosthet Dent. 2008; 100: 449-457.

11. Dagar S, Pakhan A, Thombare R, Motwani B. The evaluation of flexural strength and impact strength of heatpolymerized polymethyl methacrylate denture base resin reinforced with glass and nylon fibers: An in vitro study. $J$ Indian Prosthodont Soc. 2008 ;8: 98104.

12. Tacir I, Kama J, Zortuk M. Flexural properties of glass fiber reinforced acrylic resin polymers. Aust Dent $J$. 2008; 51(1): 52 - 56

13-Vallittu P, Lassila V. Reinforcement of acrylic resin denture base material with metal or fiber strengtheners. $J$ Oral Rehabil. $1992 ; 19: 225-230$.

14. Lambrecht J, Kydd W. A functional stress analysis of the maxillary complete denture base. $J$ Prosthet Dent. 1962; 12: 865-872.

15. Dabbar U, Huggett R, Harrison A. Denture fracture- survey. $\mathrm{Br}$ Dent $J$. 1994; 176:342-345.

16. Kim S, Watts D.The effect of reinforcement with woven E-glass fibers on the impact strength of complete dentures fabricated with high impact acrylic resin. J Prosthet Dent. 2004; 91:274280.

17. Halliday D, Resnick R, Walker J. Fandamantals of physics. $6^{\text {th }} \mathrm{ed}$. Indianapolis; John and Sons; 2001. P:144.

18. Zappini G, Kammann A, Wachter W. Comparison of fracture tests of denture base materials. J Prosthet Dent. 2003; 90:578-585.

19. Hiromori K, Fujii K, Inoue K. Visco elastic properties of denture base resins obtained by underwater test. J Oral Rehabil. 2000; 27:522-531.

20. Wong D, Cheng L, Chow T, Clark R. Effect of processing method on the dimensional accuracy and water sorption of acrylic resin dentures .J Prosthet Dent. 1999; 81:300-304.

21. Arima T, Murata H, Hamada T. The effects of cross-linking agents on the 
water sorption and solubility characteristics of denture base resin. J Oral Rehabil. 1996 ; 23(7): 476-480.

22. Yau W, Cheng Y, Clark R, Chow T. Pressure and temperature changes in heat-cured acrylic resin during processing. Dent Mater. 2002 ;18: 622629.

23. Sedda M, Borracchini A, Monticelli F. Influence of the polymerization cycle on the flexural strength of four different PMMA based heat- polymerized denture base resin. Int Dent Sou Afric. 2007; 8(3): 20-26.

24. Vergani C, Seiko Seo R, Pavarina A. Flexural strength of autopolymerizing denture reline resins with microwave post polymerization treatment. J Prosthet Dent. 2005; 93: 577-583. 